\title{
Medico-legal Aspects of Burned Cases Admitted to Burn Unit in Tanta University Hospital
}

\author{
Mona M. Heshmat, Aisha I. Maklad, Mona M. Abo El Noor, and Nadia E. Helal ${ }^{1}$
}

\footnotetext{
${ }^{1}$ Forensic Medicine and Clinical Toxicology Department, Faculty of Medicine, Tanta University, Tanta, Egypt.
}

\begin{abstract}
Background: Burns continue to be a medical, psychological and economic problem in developed and developing countries. Burns in Egypt represent a major problem as compared with heart diseases, malignancy and road accidents.

Objectives: Accordingly, this work was conducted to study the medico legal aspects of burned cases and the magnitude of burn problem in Burn Unit in Tanta University Hospital.

Study design: This study was cross sectional, conducted over six months where (160) burned cases admitted to Burn Unit in Tanta University hospital from the start of March 2013 to the end of August 2013. All the patients were included except old burn injuries. Patients were interviewed, clinically examined and investigated, and then data were collected in a specially designed sheet for every patient.

Results: One hundred and sixty cases admitted to Burn Unit in Tanta University Hospital during a period of six months from the start of March 2013 to the end of August 2013. The highest percentage of patients was among the age group less than 10 years $(38.125 \%)$. The majority of the studied cases were distributed among males $(58.1 \%)$ in rural areas $(61.9 \%)$. Burns at home constituted $(84.4 \%)$ of burns. Concerning the agent causing burn, flame constituted (51.9\%) followed by scald $(37.5 \%)$, chemical $(6.3 \%)$ and electrical burns $(4.4 \%)$. Most flame burns were due to explosion of gas cylinder. Most burns were of second degree $(49.37 \%)$, distributed all over the body $(43.8 \%)$ and involved $15-30 \%$ total body surface area (TBSA) (40\%). Accidental burns accounted for $95 \%$ of all cases followed by suicidal and homicidal cases (3.1 and $1.9 \%$ respectively). All suicidal cases were females, caused by flame and distributed all over the body with involvement of more than $60 \%$ TBSA. While homicidal cases were males in urban areas. Respiratory complications were the commonest cause of death (38.9\%). It could be concluded that intensive educational programs concerning burn dangers, proper prevention, safety measures and regular servicing of gas appliances must be followed. Psychological autopsy is needed in suicidal cases.
\end{abstract}

\section{Introduction}

$\mathrm{B}$ urns are among the most severe kind of harm that may ever affect a human being. Burns continue to be a medical, psychological and economic problem in both developed and developing countries (Karter, 2006 and Brown and Tarnowski, 2011). The majority (over 95\%) occurs in economically developing countries where prevention programs are primitive (Potokar et al., 2007).

Burns are the fourth most common type of trauma worldwide, following traffic accidents, falls, and interpersonal violence. Every year, there are approximately 195,000 deaths directly attributed to burns around the world (Peck, 2012).
Most burn injuries are caused by thermal injury including fires and scalding, while the minorities are caused by chemical exposure, electricity, and ionizing radiation (Edlich, 2010).

Most burns affect only the skin. It can also affect deeper tissues, such as muscle, bone and blood vessels. Respiratory system can be damaged in fires with possible airway obstruction, pulmonary edema and adult respiratory distress syndrome (Demling, 2006 and Boots et al., 2009). Smoke inhalation injuries account for $75 \%$ of the deaths related to fire (Morris et al., 2009).

Since burns injure skin, they impair the body's normal fluid/electrolyte balance, body temperature and physical appearance. Complications such as shock, 
infection and multiple organ dysfunction syndrome may occur (Church et al., 2006).

Burn injuries in Egypt represent a major problem as compared with heart diseases, malignancy and road accidents (Mabrouk, 1987). According to the data obtained from the Statistical Unit in Tanta University Hospital, the total number of cases admitted to the burn unit in Emergency Hospital Tanta University in the last 5 years was 1470 cases.

Sound knowledge of epidemiological characteristics and associated risk factors for burns are essential components of preventive programs. So, this work was conducted to detect the medico legal aspects of burned cases and the magnitude of burn problem in Burn Unit in Tanta University Hospital.

\section{Patients and methods}

\section{Place of the study}

This study was cross-sectional. It was conducted over six months on (160) burned cases admitted to Burn Unit in Tanta University Hospital from the start of March 2013 to the end of August 2013 with the following inclusion criteria:

- All age groups.

- All degrees of burn.

- All percentages of burned surface area.

- Recent burns.

- Referred and 1st presentation cases.

- Patients of different residence and occupations.

Old burn injuries were excluded.

\section{Methods}

Patients were interviewed and clinically examined, then data were collected in a specially designed sheet for every patient as regards:

- Name.

- Age (<10years, 10-, 20-, 30-, 40-, 50-, 60 - and $>70$ years).

- Gender (female or male).

- Residence (rural or urban).

- Time of injury (Morning, afternoon and night).

- Manner of burn injury (accidental, suicidal or homicidal).

- Causes of burn (flame, scald, chemical, electrical, radiation and inhalation injury).

- Degree of burn (first, second, third and all degrees of burn).

- Total body surface area (TBSA) affected by burn $(<15 \%, 15-30 \%, 30$ $60 \%$ or $>60 \%$ ).
- Site of burn on the body (head alone, head and neck, head and extremities, head and neck and extremities, back, upper extremities alone, lower extremities alone, both extremities or all over the body).

- Place of burn (home, work place or other place).

- Previous medical conditions, diseases, surgery and medication.

Every case will be examined clinically for:

1. Assessment of the general condition.

a. Conscious level.

b. Vital data: blood pressure, pulse, respiratory rate and temperature .

c. Cardiovascular examination.

d. Respiratory system examination.

e. Gastrointestinal examination.

2. Describing the local injury including:

a. Percentage of burned area.

b. Degree of burn.

c. Site of burned area in the body

3. Investigations including:

a. Complete blood picture

b. Random Blood Sugar (RBS)

c. Liver function tests (ALT, AST, Bilirubin, prothrombin time, serum albumin).

d. Kidney function tests (blood urea nitrogen and serum creatinine).

e. Serum electrolytes to critical patients.

f. Arterial blood gases (ABG).

4. Mode of discharge from hospital: improved, complicated, leave against medical advice or escape and death.

5. Figure graphing of the injury after taking consent from the patient if possible. Ethics approval for the study was obtained from the Research Ethics and Publications Committee of the Faculty of Medicine, Tanta University, Egypt. Privacy of all patient data was granted and there was a code number for every patient file that included all investigations.

\section{Statistics}

Data were entered into SPSS statistical program version 17, Chicago IL. Descriptive statistics were used to 
describe the sample and p-values less than or equal to 0.05 were considered to be statistically significant. The statistical test for comparison between two groups as regards qualitative data was the Chi-square test.

\section{Results}

The study was conducted on (160) cases admitted to Burn Unit in Tanta University Hospital from the start of March 2013 to the end of August 2013.

The burnt cases were studied as regards some bio-demographic data, the circumstances, causes of burn, degree of burn, total body surface area and the site from the body affected by burn as well as mode of discharge in patients with burn injuries.

Table (1) shows the distribution of burnt patients as regard age, gender and residence. There was a significant increase of burnt cases in rural areas $(\mathrm{P}=0.041)$. Most males and females were among the age group less than 10 years (38.7\% and $37.3 \%$ respectively).

Table (2) shows some characters of burn which are cause and degree of burn, total body surface area (TBSA) and site of burn from the body. The commonest agent encountered in this study was flame $(51.9 \%)$ of which explosion of gas cylinder was the major cause (Figures 1 and 2). Flame was followed by scald (37.5\%), chemical $(6.3 \%)$ and electrical $(4.4 \%)$ burns (Figures 3 and 4).

As regard time and place of burn, it is noticeable that over half of the studied cases were injured at night $52.5 \%$ and the least cases were injured in the afternoon $18.7 \%$. The current study revealed that burn at home was significantly increased $(84.4 \%)$ compared to work or other places ( $8.1 \%$ and $7.5 \%$ respectively) (table 3 ).

Table (4) shows the distribution of patients according to the manner of burn injury. There was highly significant increase in accidental burns (95\%) compared to suicidal and homicidal cases $(3.1 \%$ and $1.9 \%$ respectively).

Table (5) demonstrates that there was insignificant difference among the burnt patients as regard the manner of burn injury and age $(\mathrm{P}=0.336)$. It reveals that the highest number of accidental cases was among the age grouping less than 10years (39.5\%).

Table (6) shows that male to female percentage in accidental injuries was $59.2 \%$ to $40.8 \%$. All suicidal cases were females, while all homicidal cases were males.

There was statistically significant increase in accidental burns in both rural and urban areas $(62.5 \%$ and $37.5 \%$ respectively), $\mathrm{P}=0.049$. All homicidal cases occurred in urban areas, while $80 \%$ of suicidal cases were rural (table 7).
Table (8) demonstrates that there was also insignificant difference among the burnt patients as regard to manner of burn injury and cause of burn, $\mathrm{P}=0.024$. It was observed that accidental burn could be caused by any type of burn, mostly by flame (50\%) followed by scalds $(38.8 \%)$, while electrical burn represented the least percentage $(4.6 \%)$. Suicidal burn attempts were committed only by the use of flame, while homicidal burns were committed mostly by flame $(66.7 \%)$ and scalds (33.3\%).

There was a significant statistical difference among burnt patients as regard the manner of burn injury and degree of burn $(\mathrm{P}=0.018)$. All homicidal cases presented second degree burns. In suicidal cases, $60 \%$ presented third degree burn while most accidental burns (46.7\%) presented second degree burn (Table 9).

There was also a significant statistical difference among burnt patients according to the manner and site of burn from the body $(\mathrm{P}=0.027)$. Lesions in all suicidal cases were found in more than one site as head, neck and extremities. In the majority of homicidal cases and most of accidental cases lesions were distributed all over the body ( $66.7 \%$ and $41.4 \%$ respectively) as shown in Table 10.

Table (11) shows a significant statistical difference among the burnt patients as regard manner of burn injury and TBSA involved from the body $(\mathrm{P}=0.027)$. In all homicidal cases and most of accidental cases $(40.1 \%), 15-30 \%$ TBSA was involved, while in all suicidal cases, more than $60 \%$ TBSA was involved.

Table (12) shows that there was a significant statistical difference among the burnt patients according to mode of discharge $(\mathrm{P}=0.029)$. There was also a significant statistical difference among the burned patients as regard relation between mode of discharge and manner of burn injury (Table 13). It was noticed that $80 \%$ of suicidal cases died representing $22.2 \%$ of total deaths. As regards homicidal cases, the majority of cases $(66.7 \%)$ were complicated, while $33.3 \%$ of patients improved. The study showed that most accidental cases (38.2\%) improved followed by complicated cases $(31.6 \%)$, while the least percentage died $(9.2 \%)$.

The present study demonstrated that the highest percentage of patients with previous history of chronic illness as hypertension and bronchial asthma died (53.1\%), while the highest percentage of patients with negative history of diseases improved (42.2\%) as shown in table 14.

Figure (5) shows burnt patient with pseudomonas infection and generalized body edema. Figure (6) demonstrates that respiratory tract complications were the most common cause of death $(38.9 \%)$, followed by septicemia $(33.3 \%)$ and lastly shock $(27.8 \%)$. 
Table (1): Chi square statistical analysis of some demographic data among studied patients $(\mathrm{N}=160)$.

\begin{tabular}{|l|l|c|c|c|c|}
\hline \multicolumn{2}{|c|}{ Parameter } & $\mathbf{N}$ & $\mathbf{\%}$ & $\mathbf{X}^{\mathbf{2}}$ & $\mathbf{P}$ \\
\hline \multirow{4}{*}{ Gender } & Male & 93 & 58.1 & \multirow{2}{*}{1.635} & \multirow{2}{*}{0.224} \\
\cline { 2 - 4 } & Female & 67 & 41.8 & & \\
\hline \multirow{5}{*}{ Age } & $>10 \mathrm{y}$ & 61 & 38.125 & & \\
\cline { 2 - 4 } & $10-<20 \mathrm{y}$ & 23 & 14.375 & & \\
\cline { 2 - 4 } & $20-<30 \mathrm{y}$ & 25 & 15.625 & & \\
\cline { 2 - 4 } & $30-<40 \mathrm{y}$ & 19 & 11.875 & \multirow{3}{*}{2.635} & \multirow{3}{*}{0.096} \\
\cline { 2 - 4 } & $40-<50 \mathrm{y}$ & 21 & 13.125 & & \\
\cline { 2 - 4 } & $50-<60 \mathrm{y}$ & 5 & 3.135 & & \\
\cline { 2 - 4 } Residence & $60-<70 \mathrm{y}$ & 5 & 3.135 & & \\
\cline { 2 - 4 } & $\geq 70 \mathrm{y}$ & 1 & 0.635 & & \\
\hline & Rural & 99 & 61.9 & \multirow{2}{*}{3.258} & \multirow{2}{*}{$0.041^{*}$} \\
\hline
\end{tabular}

$N=$ number $; * P<0.05$ significant $; * * P<0.001$ highly significant

Table (2): Chi square statistical analysis of some characters of burn among studied patients (N=160).

\begin{tabular}{|c|c|c|c|c|c|}
\hline \multicolumn{2}{|r|}{ Parameter } & $\mathbf{N}$ & $\%$ & $\mathbf{X}^{2}$ & $\mathbf{P}$ \\
\hline \multirow{4}{*}{ Cause of burn } & Flame & 83 & 51.9 & \multirow{4}{*}{2.635} & \multirow{4}{*}{0.063} \\
\hline & Scalds & 60 & 37.5 & & \\
\hline & Chemical & 10 & 6.3 & & \\
\hline & Electrical & 7 & 4.4 & & \\
\hline \multirow{4}{*}{ Degree of burn } & First & 3 & 1.9 & \multirow{4}{*}{2.336} & \multirow{4}{*}{0.085} \\
\hline & Second & 74 & 46.2 & & \\
\hline & Third & 24 & 15 & & \\
\hline & All degrees & 56 & 36.9 & & \\
\hline \multirow{4}{*}{ TBSA } & $<15 \%$ & 57 & 35.6 & \multirow{4}{*}{1.951} & \multirow{4}{*}{0.096} \\
\hline & $15-30 \%$ & 64 & 40 & & \\
\hline & $30-60 \%$ & 26 & 16.3 & & \\
\hline & $>60 \%$ & 13 & 8.1 & & \\
\hline \multirow{9}{*}{ Site of burn } & Head & 5 & 3.1 & \multirow{9}{*}{2.951} & \multirow{9}{*}{0.050} \\
\hline & Head and neck & 3 & 1.9 & & \\
\hline & Head and extremities & 34 & 21.3 & & \\
\hline & Head, neck and extremities & 13 & 8.1 & & \\
\hline & Back & 1 & 0.6 & & \\
\hline & Upper extremities alone & 10 & 6.2 & & \\
\hline & Lower extremities alone & 10 & 6.2 & & \\
\hline & Upper and lower extremities & 14 & 8.8 & & \\
\hline & All over the body & 70 & 43.8 & & \\
\hline
\end{tabular}

$N=$ number; $* P<0.05$ significant; $* * P<0.001$ highly significant

Table (3): Chi square statistical analysis of time and place of burn among studied patients $(\mathrm{N}=160)$.

\begin{tabular}{|c|c|c|c|c|}
\hline \multirow{2}{*}{ Parameter } & \multicolumn{2}{|c|}{ Burned cases $(\mathrm{N}=160)$} & \multirow{2}{*}{$\mathbf{X}^{2}$} & \multirow{2}{*}{$\mathbf{P}$} \\
\hline & $\mathbf{N}$ & $\%$ & & \\
\hline \multicolumn{5}{|l|}{ Time of burn } \\
\hline Morning & 46 & 28.8 & \multirow{4}{*}{6.358} & \multirow{4}{*}{$0.027 *$} \\
\hline Afternoon & 30 & 18.7 & & \\
\hline Night & 84 & 52.5 & & \\
\hline Total & 160 & 100 & & \\
\hline \multicolumn{5}{|l|}{ Place of burn } \\
\hline Home & 135 & 84.4 & \multirow{4}{*}{11.325} & \multirow{4}{*}{$0.001 * *$} \\
\hline Work place & 13 & 8.1 & & \\
\hline Other place & 12 & 7.5 & & \\
\hline Total & 160 & 100 & & \\
\hline
\end{tabular}

$N=$ number $; * P<0.05$ significant $; * P<0.001$ highly significant 
Table (4): Chi square statistical analysis of manner of burn injury among studied patients $(\mathrm{N}=160)$.

\begin{tabular}{|l|c|c|c|c|}
\hline \multirow{2}{*}{ Manner } & \multicolumn{2}{|c|}{ Manner of burn injury } & \multirow{2}{*}{$\mathbf{X}^{\mathbf{2}}$} & \multirow{2}{*}{ P } \\
\cline { 2 - 3 } & $\mathbf{N}$ & $\mathbf{\%}$ & & \\
\hline Accidental & 152 & 95 & & \multirow{2}{*}{8.627} \\
\hline Suicidal & 5 & 3.1 & $0.001^{* *}$ \\
\hline Homicidal & 3 & 1.9 & & \\
\hline Total & 160 & 100 & & \\
\hline
\end{tabular}

$N=$ number; $* P<0.05$ significant; $* * P<0.001$ highly significant

Table (5): Chi square statistical analysis of studied patients $(\mathrm{N}=160)$ according to manner of burn injury and age.

\begin{tabular}{|c|c|c|c|c|c|c|c|c|}
\hline \multirow{3}{*}{ Age (Years) } & \multicolumn{6}{|c|}{ Manner of burn injury } & \multirow{3}{*}{$\mathbf{X}^{2}$} & \multirow{3}{*}{$\mathbf{P}$} \\
\hline & \multicolumn{2}{|c|}{ Accidental } & \multicolumn{2}{|c|}{ Suicidal } & \multicolumn{2}{|c|}{ Homicidal } & & \\
\hline & $\mathbf{N}$ & $\%$ & $\mathbf{N}$ & $\%$ & $\mathbf{N}$ & $\%$ & & \\
\hline $0-<10$ & 60 & 39.5 & 0 & 0 & 1 & 33.3 & \multirow{8}{*}{1.952} & \multirow{8}{*}{0.336} \\
\hline $10-<20$ & 21 & 13.8 & 2 & 40 & 0 & 0 & & \\
\hline $20-<30$ & 25 & 16.4 & 0 & 0 & 0 & 0 & & \\
\hline $30-<40$ & 16 & 10.5 & 1 & 20 & 2 & 66.7 & & \\
\hline $40-<50$ & 21 & 13.8 & 0 & 0 & 0 & 0 & & \\
\hline $50-<60$ & 3 & 2 & 2 & 40 & 0 & 0 & & \\
\hline $60-<70$ & 5 & 3.3 & 0 & 0 & 0 & 0 & & \\
\hline$\geq 70$ & 1 & 0.7 & 0 & 0 & 0 & 0 & & \\
\hline Total & 152 & 100 & 5 & 100 & 3 & 100 & & \\
\hline
\end{tabular}

$N=$ number; $* P<0.05$ significant $; * * P<0.001$ highly significant

Table (6): Chi square statistical analysis of studied patients $(\mathrm{N}=160)$ according to manner of burn injury and gender.

\begin{tabular}{|c|c|c|c|c|c|c|c|c|}
\hline \multirow{3}{*}{ Gender } & \multicolumn{6}{|c|}{ Manner of burn injury } & \multirow{3}{*}{$\mathbf{X}^{2}$} & \multirow{3}{*}{$\mathbf{P}$} \\
\hline & \multicolumn{2}{|c|}{ Accidental } & \multicolumn{2}{|c|}{ Suicidal } & \multicolumn{2}{|c|}{ Homicidal } & & \\
\hline & $\mathbf{N}$ & $\%$ & $\mathbf{N}$ & $\%$ & $\mathbf{N}$ & $\%$ & & \\
\hline Males & 90 & 59.2 & 0 & 0 & 3 & 100 & \multirow{3}{*}{0.857} & \multirow{3}{*}{0.753} \\
\hline Females & 62 & 40.8 & 5 & 100 & 0 & 0 & & \\
\hline Total & 152 & 100 & 5 & 100 & 3 & 100 & & \\
\hline
\end{tabular}

$N=$ number; $* P<0.05$ significant; $* * P<0.001$ highly significant

Table (7): Chi square statistical analysis of studied patients $(\mathrm{N}=160)$ according to manner of burn injury and residence.

\begin{tabular}{|c|c|c|c|c|c|c|c|c|}
\hline \multirow{3}{*}{ Residence } & \multicolumn{6}{|c|}{ Manner of burn injury } & \multirow{3}{*}{$\mathbf{X}^{2}$} & \multirow{3}{*}{$\mathbf{P}$} \\
\hline & \multicolumn{2}{|c|}{ Accidental } & \multicolumn{2}{|c|}{ Suicidal } & \multicolumn{2}{|c|}{ Homicidal } & & \\
\hline & $\mathbf{N}$ & $\%$ & $\mathbf{N}$ & $\%$ & $\mathbf{N}$ & $\%$ & & \\
\hline Rural & 95 & 62.5 & 4 & 80 & & & \multirow{3}{*}{5.592} & \multirow{3}{*}{$0.049 *$} \\
\hline Urban & 57 & 37.5 & 1 & 20 & 3 & 100 & & \\
\hline Total & 152 & 100 & 5 & 100 & 3 & 100 & & \\
\hline
\end{tabular}

$N=$ number; $* P<0.05$ significant; $* * P<0.001$ highly significant

Table (8): Chi square statistical analysis of studied patients $(\mathrm{N}=160)$ according to manner of burn injury and cause of burn.

\begin{tabular}{|l|c|c|c|c|c|c|c|c|}
\hline \multirow{3}{*}{ Cause of burn } & \multicolumn{6}{|c|}{ Manner of burn injury } & \multirow{3}{*}{$\mathbf{X}^{\mathbf{2}}$} & \multirow{3}{*}{ P } \\
\cline { 2 - 7 } & \multicolumn{2}{|c|}{ Accidental } & \multicolumn{2}{|c|}{ Suicidal } & \multicolumn{1}{|c|}{ Homicidal } & & \\
\cline { 2 - 7 } & $\mathbf{N}$ & $\mathbf{\%}$ & $\mathbf{N}$ & $\mathbf{\%}$ & $\mathbf{N}$ & $\mathbf{\%}$ & & \\
\hline Flame & 76 & 50 & 5 & 100 & 2 & 66.7 & & \\
\hline Scald & 59 & 38.8 & 0 & 0 & 1 & 33.3 & \multirow{3}{*}{5.326} & \multirow{2}{*}{$0.024^{*}$} \\
\hline Chemical & 10 & 6.6 & 0 & 0 & 0 & 0 & & \\
\hline Electrical & 7 & 4.6 & 0 & 0 & 0 & 0 & & \\
\hline Total & 152 & 100 & 5 & 100 & 3 & 100 & & \\
\hline
\end{tabular}

$N=$ number; $* P<0.05$ significant; $* * P<0.001$ highly significant 
Table (9): Chi square statistical analysis of studied patients according to manner of burn injury and degree of burn.

\begin{tabular}{|c|c|c|c|c|c|c|c|c|}
\hline \multirow{3}{*}{ Degree of burn } & \multicolumn{6}{|c|}{ Manner of burn injury } & \multirow{3}{*}{$\mathbf{X}^{2}$} & \multirow{3}{*}{$\mathbf{P}$} \\
\hline & \multicolumn{2}{|c|}{ Accidental } & \multicolumn{2}{|c|}{ Suicidal } & \multicolumn{2}{|c|}{ Homicidal } & & \\
\hline & $\mathbf{N}$ & $\%$ & $\mathbf{N}$ & $\%$ & $\mathbf{N}$ & $\%$ & & \\
\hline First & 3 & 2 & 0 & 0 & 0 & 0 & \multirow{4}{*}{12.36} & \multirow{4}{*}{$0.018^{*}$} \\
\hline Second & 71 & 46.7 & 0 & 0 & 3 & 100 & & \\
\hline Third & 21 & 13.8 & 3 & 60 & 0 & 0 & & \\
\hline All degrees & 57 & 37.5 & 2 & 40 & 0 & 0 & & \\
\hline Total & 152 & 100 & 5 & 100 & 3 & 100 & & \\
\hline
\end{tabular}

$N=$ number; $* P<0.05$ significant $; * * P<0.001$ highly significant

Table (10): Chi square statistical analysis of studied patients $(\mathrm{N}=160)$ according to manner of burn injury and site of burn.

\begin{tabular}{|c|c|c|c|c|c|c|c|c|}
\hline \multirow{3}{*}{ Site of burn } & \multicolumn{6}{|c|}{ Manner of burn injury } & \multirow{3}{*}{$\mathbf{X}^{2}$} & \multirow{3}{*}{$\mathbf{P}$} \\
\hline & \multicolumn{2}{|c|}{ Accidental } & \multicolumn{2}{|c|}{ Suicidal } & \multicolumn{2}{|c|}{ Homicidal } & & \\
\hline & $\mathbf{N}$ & $\%$ & $\mathbf{N}$ & $\%$ & $\mathbf{N}$ & $\%$ & & \\
\hline Head & 5 & 3.3 & 0 & 0 & 0 & 0 & \multirow{9}{*}{6.369} & \multirow{9}{*}{$0.027 *$} \\
\hline Head and neck & 3 & 1.9 & 0 & 0 & 0 & 0 & & \\
\hline Head and extremities & 33 & 21.7 & 0 & 0 & 1 & 33.3 & & \\
\hline Head, neck and extremities & 13 & 8.6 & 0 & 0 & 0 & 0 & & \\
\hline Back & 1 & 0.7 & 0 & 0 & 0 & 0 & & \\
\hline Upper extremities alone & 10 & 6.6 & 0 & 0 & 0 & 0 & & \\
\hline Lower extremities alone & 10 & 6.6 & 0 & 0 & 0 & 0 & & \\
\hline Upper and lower extremities & 14 & 9.2 & 0 & 0 & 0 & 0 & & \\
\hline More than one site & 63 & 41.4 & 5 & 100 & 2 & 66.7 & & \\
\hline Total & 152 & 100 & 5 & 100 & 3 & 100 & & \\
\hline
\end{tabular}

$N=$ number; $* P<0.05$ significant $; * P<0.001$ highly significant

Table (11): Chi square statistical analysis of studied patients $(\mathrm{N}=160)$ according to manner of burn injury and TBSA.

\begin{tabular}{|c|c|c|c|c|c|c|c|c|}
\hline \multirow{3}{*}{ TBSA } & \multicolumn{6}{|c|}{ Manner of burn injury } & \multirow{3}{*}{$\mathbf{X}^{2}$} & \multirow{3}{*}{$\mathbf{P}$} \\
\hline & \multicolumn{2}{|c|}{ Accidental } & \multicolumn{2}{|c|}{ Suicidal } & \multicolumn{2}{|c|}{ Homicidal } & & \\
\hline & $\mathbf{N}$ & $\%$ & $\mathbf{N}$ & $\%$ & $\mathbf{N}$ & $\%$ & & \\
\hline$<15 \%$ & 57 & 37.5 & 0 & 0 & 0 & 0 & \multirow{4}{*}{6.358} & \multirow{4}{*}{$0.027^{*}$} \\
\hline $15-<30 \%$ & 61 & 40.1 & 0 & 0 & 3 & 100 & & \\
\hline $30-<60 \%$ & 26 & 17.1 & 0 & 0 & 0 & 0 & & \\
\hline$\geq 60 \%$ & 8 & 5.3 & 5 & 100 & 0 & 0 & & \\
\hline Total & 152 & 100 & 5 & 100 & 3 & 100 & & \\
\hline
\end{tabular}

TBSA = total body surface area; $N=$ number; $* P<0.05$ significant; $* * P<0.001$ highly significant

Table (12): Chi square statistical analysis of mode of discharge among studied patients $(\mathrm{n}=160)$.

\begin{tabular}{|c|c|c|c|c|}
\hline \multirow{2}{*}{ Mode of discharge } & \multicolumn{2}{|c|}{ Mode of discharge } & \multirow{2}{*}{$\mathbf{X}^{2}$} & \multirow{2}{*}{$\mathbf{P}$} \\
\hline & $\mathbf{N}$ & $\%$ & & \\
\hline Improvement & 59 & 36.9 & \multirow{4}{*}{1.855} & \multirow{4}{*}{$0.029 *$} \\
\hline Complicated & 50 & 31.3 & & \\
\hline Escaped & 33 & 20.6 & & \\
\hline Death & 18 & 11.2 & & \\
\hline Total & 160 & 100 & & \\
\hline
\end{tabular}

$N=$ number $; * P<0.05$ significant $; * P<0.001$ highly significant 
Table (13): Chi square statistical analysis of studied patients $(\mathrm{N}=160)$ according to manner of burn injury and mode of discharge.

\begin{tabular}{|c|c|c|c|c|c|c|c|c|}
\hline \multirow{3}{*}{ Mode of discharge } & \multicolumn{6}{|c|}{ Manner of burn injury } & \multirow{3}{*}{$\mathbf{X}^{2}$} & \multirow{3}{*}{$\mathbf{P}$} \\
\hline & \multicolumn{2}{|c|}{ Accidental } & \multicolumn{2}{|c|}{ Suicidal } & \multicolumn{2}{|c|}{ Homicidal } & & \\
\hline & $\mathbf{N}$ & $\%$ & $\mathbf{N}$ & $\%$ & $\mathbf{N}$ & $\%$ & & \\
\hline Improved & 58 & 38.2 & 0 & 0 & 1 & 33.3 & \multirow{4}{*}{1.33} & \multirow{4}{*}{$0.028 *$} \\
\hline Complicated & 48 & 31.6 & 0 & 0 & 2 & 66.7 & & \\
\hline Escaped & 32 & 21 & 1 & 20 & 0 & 0 & & \\
\hline Died & 14 & 9.2 & 4 & 80 & 0 & 0 & & \\
\hline Total & 152 & 100 & 5 & 100 & 3 & 100 & & \\
\hline
\end{tabular}

$N=$ number $; * P<0.05$ significant; $* * P<0.001$ highly significant

Table (14): Chi square statistical analysis of studied patients $(\mathrm{N}=160)$ according to mode of discharge and previous medical history.

\begin{tabular}{|c|c|c|c|c|c|c|}
\hline \multirow{3}{*}{ Mode of discharge } & \multicolumn{4}{|c|}{ Previous medical history } & \multirow{3}{*}{$\mathbf{X}^{2}$} & \multirow{3}{*}{$\mathbf{P}$} \\
\hline & \multicolumn{2}{|c|}{ Positive } & \multicolumn{2}{|c|}{ Negative } & & \\
\hline & $\mathbf{N}$ & $\%$ & $\mathbf{N}$ & $\%$ & & \\
\hline Improved & 5 & 15.6 & 54 & 42.2 & \multirow{5}{*}{1.529} & \multirow{5}{*}{$0.062 *$} \\
\hline complicated & 7 & 21.9 & 43 & 33.5 & & \\
\hline Escaped & 3 & 9.4 & 30 & 23.4 & & \\
\hline Death & 17 & 53.1 & 1 & 0.9 & & \\
\hline Total & 32 & 100 & 128 & 100 & & \\
\hline
\end{tabular}

$N=$ number $; * P<0.05$ significant; $* * P<0.001$ highly significant

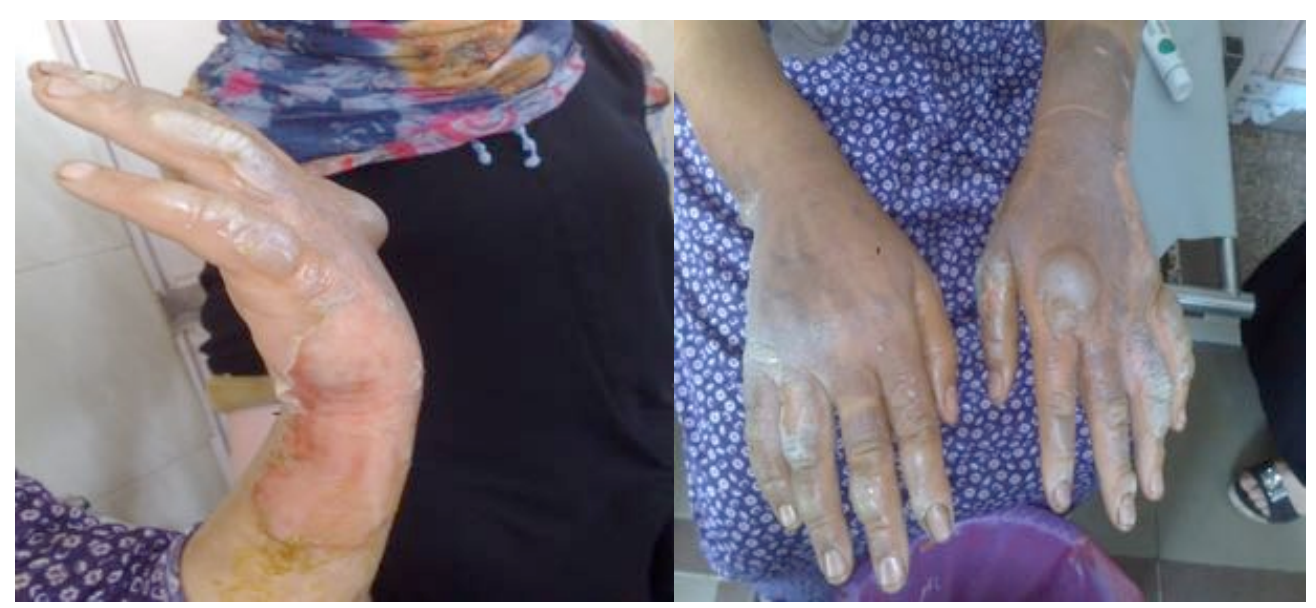

Figure (1): 51y old female with accidental deep second degree flame burn in both hands and wrists. Cause was explosion of a gas cylinder at home.

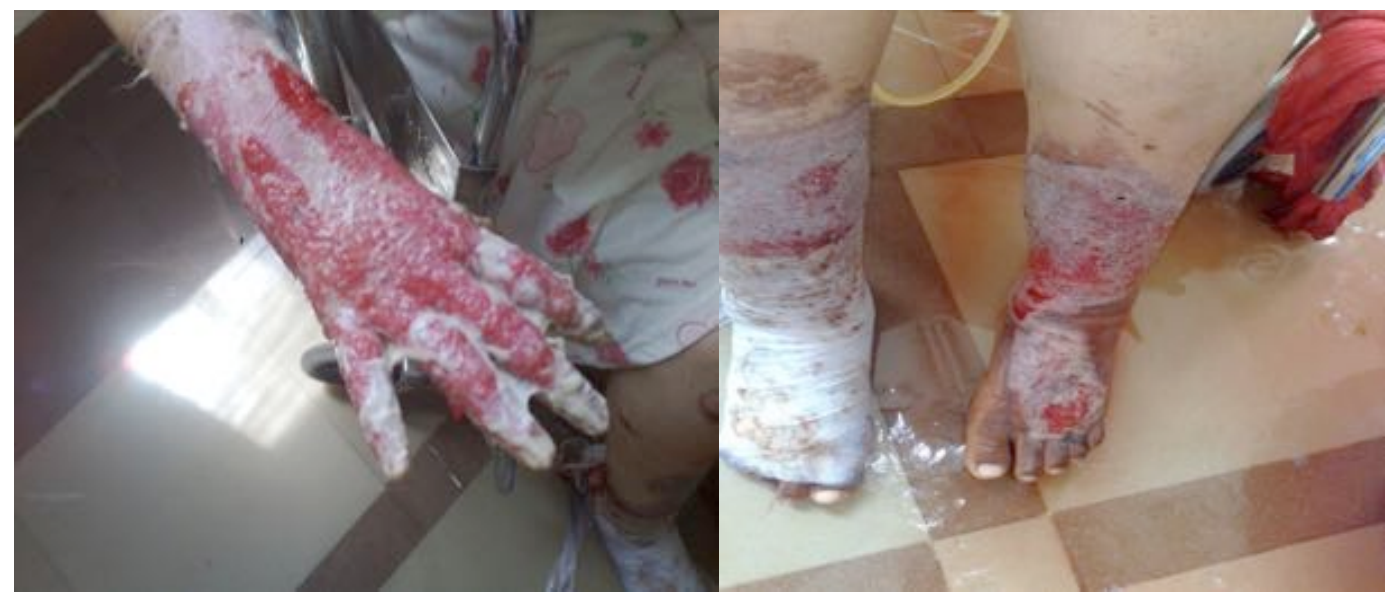

Figure (2): Female patient aged 18y with accidental flame burn at home while cooking in her face (second degree) and in hands, wrists, forearms and legs below knee joints (third degree). 
Figure (3): 18 months old male child with accidental deep second degree scald by hot water affecting front of chest, left arm and face.

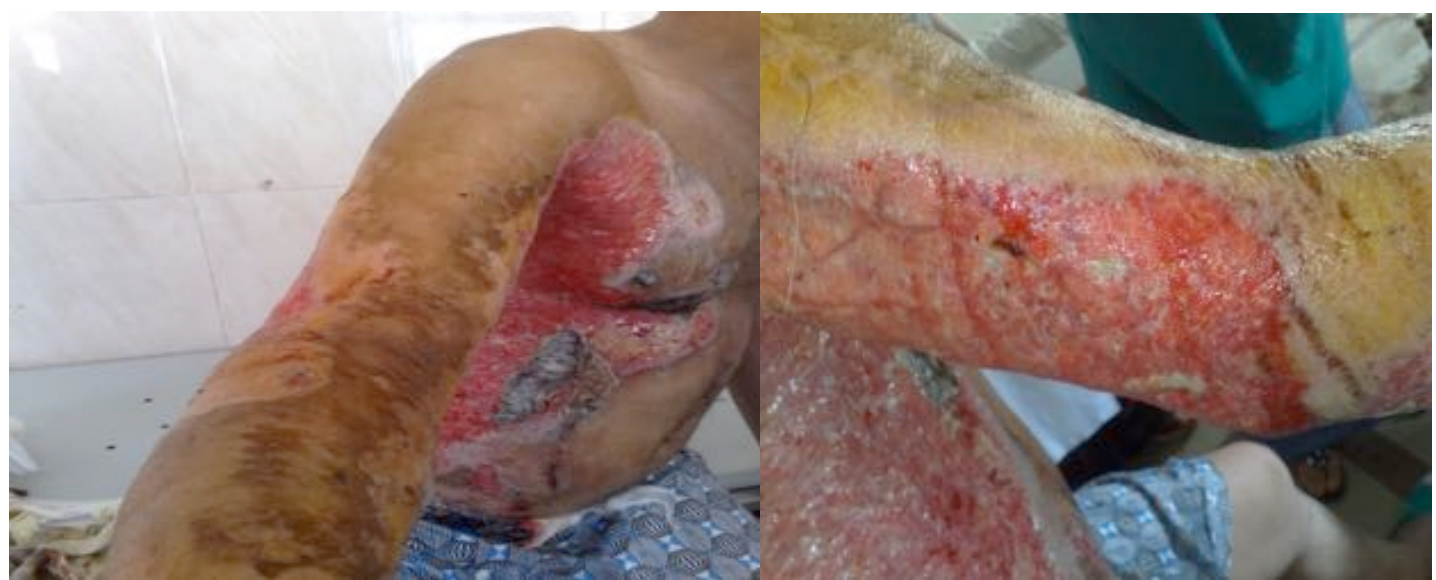

Figure (4): 45y old male with accidental third degree electrical burn involving right side of the trunk, right arm and right forearm at his work place in Al-Mehala textile factory.

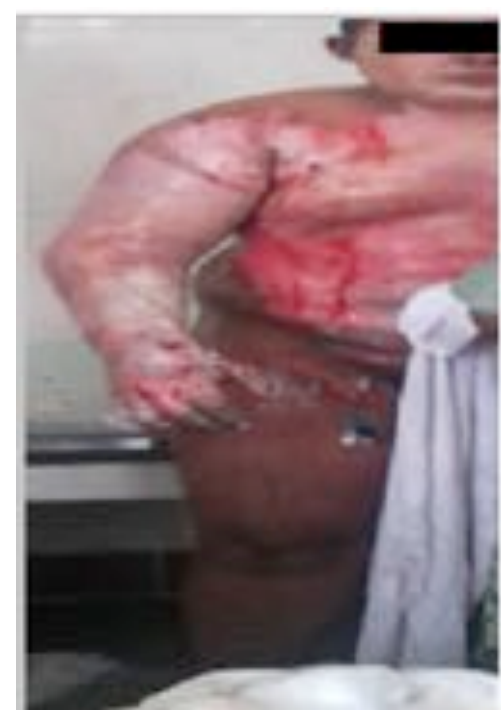

Figure (5): $18 \mathrm{y}$ old male with accidental third degree flame burn in the face, neck m chest front, abdomen, front of both thighs and both upper limbs at home. The patient was complicated with wound infection with pseudomonas and generalized edema. 


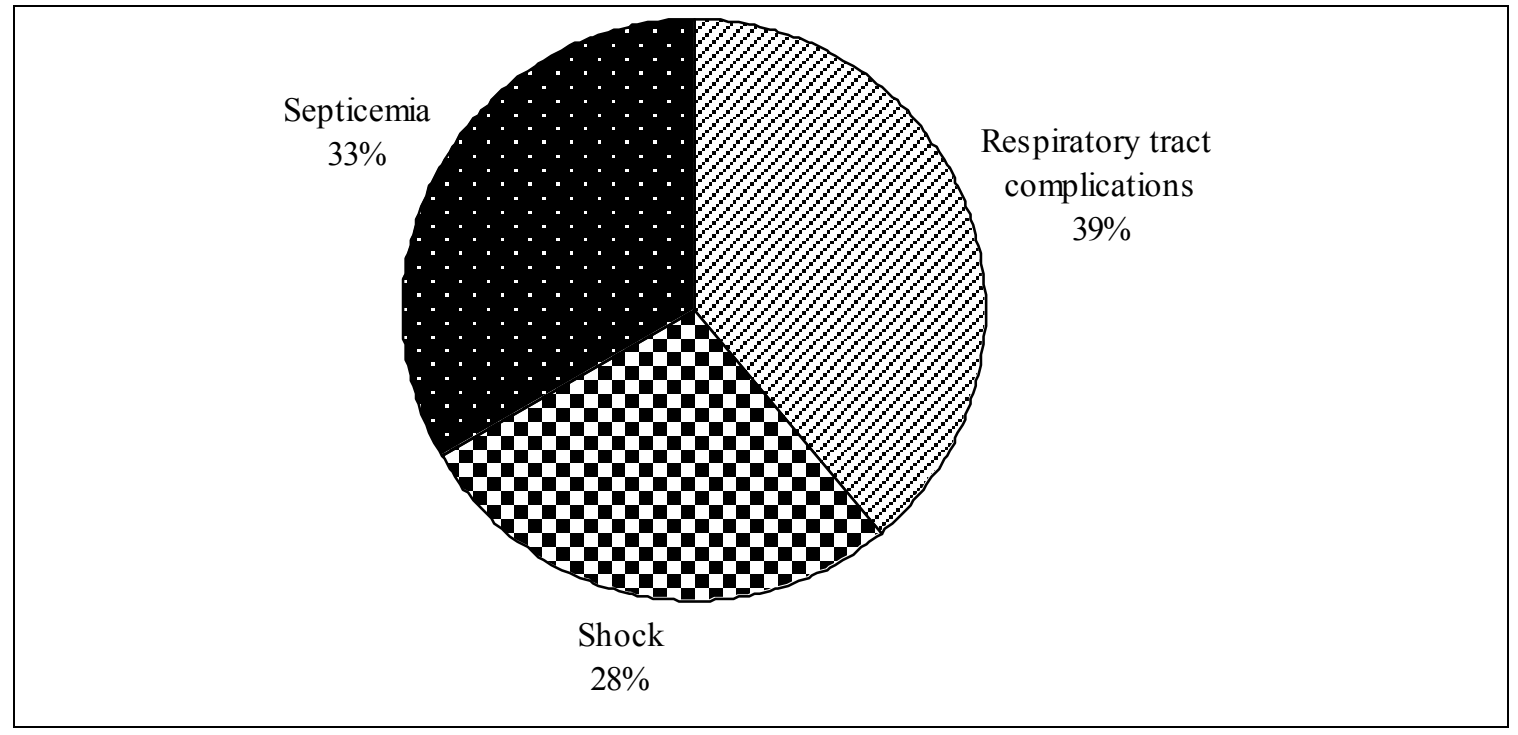

Figure (6): Distribution of dead burned patients with burn injuries by cause of death $(\mathrm{N}=18)$.

\section{Discussion}

Burns are one of the most serious conditions encountered in medicine and constitute a significant global burden of diseases that are preventable (Al-Shaqsi et al., 2013).

In the present study, there were 160 cases admitted to Burn Unit in Tanta University Hospital during a period of six months from the start of March (2013) to the end of August (2013).

The present study revealed that the highest percentage of patients was among the age group less than 10 years $(38.125 \%)$. Similarly, Hassen et al., (2010) found that $61 \%$ of burned patients in Assuit University Hospital Burn Unit were less than 5 years old. This may be explained by unawareness of children about dangerous substances and exploring nature of boys of this age being more active. Sometimes, there is lack of supervision from the parents and insufficiencies of security preparations in crowded houses especially in low socioeconomic classes (Attia et al., 1997). On the other hand, Hemeda et al., (2003) reported that (61\%) of patients admitted to Ain Shams University Burn Unit were adults, while children ( $0-14$ years) accounted for $(39 \%)$. This reflects the high exposure of middle age groups to hazards of burn as they are generally active and exposed to danger either in home or at work (Akther et al., 2010).

The current study revealed that there was male predominance over females $(58.1 \%$ and $41.9 \%$ respectively). These results were in agreement with the study of Othman, (2010) in Sulaymaniyah, Iraq. This may be due to high exposure of males to industrial and recreational burns, in addition to fire causing activities as smoking and careless handling of inflammable materials (Attia et al., (1997). On the other hand, Bhardwaj and Sinha, (2012) found that burned females were more common than males in Chiraya Hospital, Bhopal, India (54.7\% and $45.3 \%$ respectively).
It was noticed that cases from rural areas were more than those from urban areas $(61.9 \%$ and $38.1 \%$ respectively). These results were in line with those obtained by Akther et al., (2010) in Wardha Burn Unit, India. This could be explained on the basis that rural areas are characterized by inadequate safety measures and the traditional kerosene stove, which is used extensively in slum areas (Hassen et al., (2010).While, these results were the reverse with Fernández-Morales et al., (1997) who reported more prevalence of burns in urban areas $(89.5 \%)$ in cases admitted to Malaga University Hospital Burn Unit, Spain.

It's noticeable that, over half of the studied cases were injured at night $(52.5 \%)$. This was in agreement with the work of Afify et al., (2012) who conducted the study at Zeinhom Morgue of Forensic Medicine Institute, Cairo. Whereas, the results were in contrary with Hassen et al., (2010) who reported that most cases admitted to the Burn Unit in Assuit University Hospital were injured in the afternoon while the family is crowded preparing the mean meal of the day. Night burns in the present study suggested that there was a relation between people's habits to still awake for late times during night in summer seasons with prolonged activity.

Regarding burn incident location, the current study revealed that $84.4 \%$ of burns occurred at home. This figure was just like that reported by Hassen et al., (2010) in Assuit University Hospital Burn Unit. This could be attributed to the fact that the vast majority of burn victims were children in the current study that spent most of the day at home being at high risk of burn injury (Alavi et al., 2012). Conversely, Zarei et al., (2011) in Tehran, Iran reported that work related burns constituted $(21.7 \%)$ of all burned cases. This may be due to better home safety in industrialized countries (Attia et al., 1997). 
Considering the agent causing burn injury in this study, flame constituted $(51.9 \%)$, followed by scald, chemical and electrical burns $(37.5 \%, 6.2 \%$ and $4.4 \%$ respectively). There were no radiation burns or inhalation injuries observed during the period of this study. These results were just like studies of Afify et al., (2012) in Cairo. This is explained by use of oil for lamps in villages, candle for lighting, unsafe gas stoves and open coal and wood fires for warmth and cooking (Hassen et al., 2010). Whereas, Arslan et al., (2013) in Istanbul, reported that scald burn ranked first among causes of burn $(85.6 \%)$. This could be attributed to the developmental stage of such countries (Attia et al., 1997).

The current study reported that, second degree burns were the commonest $(46.2 \%)$. This was in agreement with El-Zuway and Heshmat, (2007) in AlJala Hospital in Benghazi, Libya. This could be a reflection of the high incidence of scald injuries in this study which generally causes more or less superficial burns (Ali, 1997). On the other hand, Jaiswal et al., (2007) reported that third degree burns were the commonest degree of burn among burned cases in Indore, India.

In this study, it was found that, the majority of burns were distributed all over the body (43.7\%). Similarly, Han et al., (2005) reported that (74\%) of cases admitted to Hallym Burn Center in Seoul, Korea were presented by multiple burn sites. Othman, (2010) explained that burn injuries are not commonly limited to isolated parts of the body but affect more than one area. Whereas Ali, (1997) reported that the commonest sites of burn were the lower extremities (66\%) among cases admitted in King Fahd Hospital in Al-Baha, Saudi Arabia.

It was noticed that (40\%) of cases had $15-30 \%$ TBSA, while only $(8.1 \%)$ had more than $60 \%$ TBSA. Similarly, El- Farouny et al., (2007) found that (52.2\%) of cases admitted to Minoufiya University hospital Burn Unit were affected by less than $25 \%$ TBSA. This could be attributed to scald burn prevalence among children which are usually less extensive causing superficial burns (Watson, 1989). In contrast, Attia et al., (1997) found the majority of burnt cases in Alexandria University Hospital Burn Unit were presented with 40-100\%.

Considering the manner of burn injury, the majority of burn incidents were accidental in nature (95\%), while suicidal and homicidal cases constituted (3.1\% and $1.9 \%$ respectively). These findings were in line with Afify et al., (2012) in Zeinhom morgue of Forensic Medicine Institute, Cairo and Othman, (2010) in Sulaymaniyah, Iraq. This may be attributed to the individual carelessness while handling fires and lack of safety procedures especially the appliances used for cooking, heating, and lighting purposes without proper precautions at home and work (Bhardwaj and Sinha, 2012). The lower incidence of suicidal cases may be attributed to the non pleasant nature of the trial; it has a very painful outcome (Ali, 1997). The most frequently reported precipitating factors for intentional burns are marital problems, psychological and psychiatric disorders, family problems, poverty and emotional relationships (Othman, 2010).

It was noted that, the majority of accidental cases $(39.5 \%)$, were children below 10 years, while there was no suicidal attempt among children. These results were in accordance with El-Zuway and Heshmat, (2007) in Benghazi, Libya. Suicidal attempts occurred only in females mainly in the age group 10-20y and 50-60y ( $40 \%$ each). These results were similar to those reported by Othman (2010) in Sulaymaniyah, Iraq. This could be explained on the basis that, females are more involved in domestic burn injuries, especially in rural areas, where the sources of both flame and scald burns are usually present and available for them as a method for suicide (Alavi et al., 2012). On the other hand, El-Zuway and Heshmat , (2007) reported that suicidal attempts were equal in males and females among cases admitted to AlJala Hospital, Benghazi, Libya. Homicidal cases in the current series were males mainly in the age group $30-40 \mathrm{y}$ (66.7\%). These results partially coincided with Akther et al., (2010) in Wardha Burn Unit, India who reported that the most homicidal cases were among the age group 2140 years $(2.24 \%)$, but they reported that the main homicidal cases were females.

It was observed that the majority of accidental and suicidal cases were rural $(62.5 \%$ and $80 \%$ respectively). The lack of individual safety precautions in rural areas, illiteracy and low socioeconomic standards of living raises the incidence of both intentional and non intentional burns (Alavi et al., 2012).

The current study revealed that, flame burns were the commonest among accidental, suicidal and homicidal cases $(50 \%, 100 \%$, and $66.7 \%$ respectively). As regards the source of flame, portable pressure kerosene stoves were the most common source (Othman, 2010). These findings coincided with El- Farouny et al., (2007) in Minoufiya and Wasiak et al., (2009) in Victoria Emergency Hospital, Australia who reported that suicidal burn cases were mainly attempted by flame. On the other hand, Justin-Temu et al., (2008) reported that (80\%) of homicidal burned cases admitted to hospitals of Dar Es Salaam City, Tanzania were caused by hot fluid poured over the victim.

The deeper injuries in suicidal burns noticed in the current study may be related to the causative agent that was flame in all cases which usually produces extensive full thickness burns especially if accelerant as kerosene was used which is a common method of suicide in developing countries like Egypt (Donne et al., 2004). Burns were distributed all over the body in suicidal and homicidal cases relative to accidental cases (100\%, $66.7 \%$ and $41.4 \%$ respectively). This was in contrary to Wasiak et al., (2009) in Victoria Hospitals, Australia who found that intentional self inflicted burn cases mainly affected upper extremities (52\%), while the trunk was the commonest site in homicidal cases $(30 \%)$. 
Moreover, all suicidal cases were presented with more than $60 \%$ TBSA. These findings were in agreement with Alavi et al., (2012) who found that intentional burn was significantly related to higher TBSA among cases admitted to Rasht Burn Unit, Iran. Othman, (2010) stated that self inflicted burns were usually deeper and more extensive.

Considering the outcome of patients in the current study, $(36.9 \%)$ of patients improved, followed by complicated cases $(31.3 \%)$, while $(11.2 \%)$ of the studied cases died. This was in line with El-Farouny et al., (2007) who reported 47\% improvement among burnt cases in Minoufiya University Hospital Burn Unit. Whereas, the mortality rate was widely variable as it ranged from (13.1\%) in the study of Hassen et al., (2010) in Assuit, Egypt, (2.2\%) in the study of El-Zuway and Heshmat, (2007) in Benghazi, Libya and (62.4\%) in the study of Jaiswal et al., (2007) in Indore, India. This wide difference may be due to difference in manner of injury, facilities and regimens of treatment in every country and in different burn centers (Akther et al., 2010).

In the present study, $80 \%$ of suicidal cases died. Similarly, El-Farouny et al., (2007) in Minoufiya reported that suicidal cases mainly died or complicated (7.4\% and 3.6\% respectively). Donne et al., (2004) stated that self immolation burns had usually deep and extensive TBSA and associated with higher mortality rates

The current study revealed that the majority of accidental cases improved (38.2\%). These results were in agreement with El- Farouny et al., (2007) in Minoufiya. The current study revealed that there were no deaths among homicidal cases. Whereas, Waisak et al., (2009) in Victoria hospitals, Australia reported that homicidal cases were $(25 \%)$ of all deaths. This wide difference may be due to longer study period and larger study sample in Waisak et al., (2009) study.

The present study revealed that there was a significant increase of death rates among cases with previous medical history of chronic illness if compared with those with negative history of diseases $(53.1 \%$ and $0.9 \%$ respectively). These findings coincided with the work of Mabrouk et al., (2003) who found 70.9\% of burn deaths among cases admitted to Ain Shams University Hospital Burn Unit were associated with chronic illnesses as diabetes and cardiovascular diseases.

In the present study, respiratory tract complications ranked first among causes of death (38.9\%), followed by septicemia $(33.3 \%)$ while shock constituted $(2.8 \%)$. These findings were in contrary to ElFarouny et al., (2007) who reported that septicemia was the leading cause of death $(33.3 \%)$, followed by respiratory tract complications (29.7\%) among cases admitted to Minoufiya University Hospital Burn Unit. Church et al., (2006) explained that significant thermal injuries induce a state of immunosuppression predisposing burn patients to infectious complications. Moreover, the development of antibiotic resistance during treatment and acquired nasocomial infections raises the possibility of development of chest infections. Additionally, most cases in the present study occurred indoor with much smoke inhalation and involved more than one site of the body including face. This raises the possibility of occurrence of respiratory tract complications.

\section{Conclusion}

In the present study, one hundred and sixty cases were admitted to Burn Unit in Tanta University Hospital, Egypt during a period of six months from the start of March 2013 to the end of August 2013. The highest percentage of patients was among the age group less than 10 years $(38.125 \%)$. The majority of the studied cases were males $(58.1 \%)$ in rural areas $(61.9 \%)$. Burns at home constituted $84.4 \%$. Considering the agent causing burn, Flame was first $(51.9 \%)$ followed by scalds (37.5\%), chemical (6.3\%) and electrical burns (4.4\%). Most flame burns were due to explosion of gas cylinder. Most burns were of second degree (49.37\%), distributed all over the body (43.8\%) and involved 15-30\% TBSA (40\%). Accidental burns accounted for $95 \%$ of all cases followed by suicidal and homicidal cases (3.1 and 1.9\% respectively). All suicidal cases were females, caused by flame, distributed all over the body with involvement of more than $60 \%$ TBSA. While homicidal cases were males in urban areas. Respiratory complications were the cause of death in $38.9 \%$ of burned cases.

\section{Recommendations}

From data detected in this study, we recommend an intensive educational program about burn dangers, proper prevention, first aids of burns and safety measures at home and work to increase public awareness especially children and their parents as well as old age caregivers. Safety precautions about manufacturing and using gas cylinders with regular servicing of gas appliances must be followed. Psychological autopsy is needed in suicidal cases. Physicians and surgeons should be aware about medico legal aspects of burn injury and importance of careful fulfillment of medico legal reports for all burn cases.

\section{References}

Afify MM, El Desouky NA, Mahmoud NF, et al., (2012): Fatal burn injuries: A five years retrospective autopsy study in Cairo city, Egypt. Egyptian Journal of Forensic Science. 2(4):117-122.

Akther JM, Nerker NE, Reddy PS et al., (2010): Epidemiology of Burned Patients Admitted in Burn Unit of a Rural Tertiary Teaching Hospital. Pravara Medical Review Journal; 2(4): 11:17.

Alavi CE, Salehi SH, Tolouei M, et al., (2012): Epidemiology of Burn Injuries at a Newly Established Burn Care Center in Rasht. Trauma Monthly; 17(3): 341-6. 
Ali M H (1997): Pattern of Burn Injuries at King Fahd Hospital, Al-Baha: A Study of 277 Cases. Annals of Saudi Medicine; 17 (1); 104-107.

Al-Shaqsi S, Al-Bulushi T and Al-Kashmiri A (2013): Epidemiology of burns undergoing hospitalization to the National Burn Unit in the Sultanate of Oman: A-25 year review. Burns; 4179(13): 114-9.

Arslan H, Baran KUL, Derebasinlloğlu H et al., (2013): Epidemiology of pediatric burn injuries in Istanbul, Turkey. Turkish Journal of Trauma and Emergency Surgery; 19 (2):123-126.

Attia AF, Sherif AA, Mandil AM, et al., (1997): Epidemiological and sociocultural study of burn patients in Alexandria, Egypt. Eastern Mediterranean Health Journal; 3(3): 452-461.

Bhardwaj S D and Sinha U (2012): An epidemiological survey of burn injuries in rural area, Bhopal: A cross-sectional study. Indian Journal of Burns; 20(1): 62-5.

Boots RJ, Dulhunty JM, Joel M, et al., (2009): Respiratory Complications in Burns. An Evolving Spectrum of Injury. Clinical Pulmonary Medicine; 16(3): 132-136.

Brown R T and Tarnowski K J (2011): Pediatric burns. In: Roberts M C and Steele R G, eds. Handbook of Pediatric Psychology. New York, NY: Guildford Press: 114-129.

Church D, Elsayed S, Reid O, et al., (2006): Burn wound infections. Clinical Microbiology Reviews; 19(2): 403-434.

Demling R H (2006): Burn and other thermal injuries. In: Current surgical diagnosis and treatment. 13 edition. USA: McGraw-Hill: 211-219. Chapter 14. From/www.ovid.com.

Donne J, Dunn KW, Greenbaum AR, et al., (2004): Intentional burn injury: An evidence-based clinical and forensic review. Burns; 628-642.

Edlich RF (2010): Thermal burns. In: de la Torne J I et al editor. From/www.e medicine.medscape.com.

El-Farouny R H, Badawi S M and Girgis N F (2007): A study of the medico-legal aspects of burn injury cases admitted to burn unit in Minoufiya University Hospital. M.Sc. Thesis for Minoufiya University.

El-Zuway R M A and Heshmat M M (2007): Study of patterns of Burn Injuries in Benghazi-Libya. M.Sc. Thesis for Garyounis University.

Fernández-Morales E, Gálvez-Alcaraz L, FernándezCrehuet-Navajas J, et al., (1997): Epidemiology of burns in Malaga, Spain. Burns; 23 (4): 323332.

Han TH, Kim JH, Yang MS, et al., (2005): A retrospective analysis of 19,157 burns patients: 18-year experience from Hallym Burn Center in Seoul, Korea. Burns; 31(4): 465-70.

Hassen Y S, Makboul M, Taha O, et al., (2010): Upper Egypt Experience in Management of Paediatric Burn: The Last Six Years. Annuals of Burns and Fire Disasters; 23(3): 116-119.

Hemeda M, Mabrouk A and Maher A (2003): Epidemiology of burns admitted to Ain Shams University Burn Unit, Cairo, Egypt. Burns; 29: 353-358.

Jaiswal A K, Aggarwal H, Solanki P, et al., (2007): Epidemiological and socio-cultural study of burn patients in M. Y. Hospital, Indore, India. Indian Journal of Plastic Surgery; 40:158-63.

Justin-Temu M, Rimoy G, Premji Z, et al., (2008): Causes, Magnitude and Management of Burns in Under-fives in District Hospitals in Dar Es Salaam, Tanzania. East African Journal of Public Health; 5(1): 38-42.

Karter MJ (2006): Fire loss in United States during 2005, abridged report. Quincy (MA): National Fire Protection Association, Fire Analysis and Research Division.

Mabrouk RAW (1987): Burn injuries in EgyptIncidence and management. Annuals of medbc.com. 1(1): 21.

Mabrouk A, Maher A and Nasser S (2003): An epidemiologic study of elderly burn patients in Ain Shams University Burn Unit, Cairo, Egypt. Burns; 29: 687-690.

Morris M J, Sterner J B and Zanders T B, et al., (2009): Inflammatory mediators in smoke inhalation injury. Inflammation and Allergy-Drug Targets; 8(1): 63-9.

Othman N, (2010): Epidemiology of Burn Injuries in Sulaymaniah Province of Iraq. PhD. Thesis for University of Nottingham, Iraq.

Peck MD (2012): Epidemiology of burns throughout the World. Part II: intentional burns in adults. Burns; 38(5): 630-7.

Potokar T, Chamania S and Ali, S (2007): International network for training, education and research in burns. Indian Journal of Plastic Surgery; 40:107.

Wasiak J, Spinks A, Ashby K, et al., (2009): The epidemiology of burn injuries in an Australian setting, 2000-2006. Burns; 35(8): 1124-32.

Watson A A (1989): Forensic medicine, a handbook for professionals. London: Gower Publishing Company Ltd: 211-220.

Zarei M R, Dianat S, Eslami V, et al., (2011): Factors associated with mortality in adult hospitalized burn patients in Tehran. Turkish Journal of Trauma and Emergency Surgery; 17(1):61-5. 
الملخص العربي

\section{الأوجه الطبية الشرعية لحالات الحروق الواردة لوحدة الحروق بمستشفى الطوارئ الجامعي بطنطا}

منى محمد حشمت وعائشة إبراهيم مقلا و منى محمد أبو النور و نادية عزت هلال 1

تستمر الحروق مشكلة طبية ونفسية واقتصادية في البلدان المتقدمة والنامية. وتشكل الحروق في مصر مشكلة

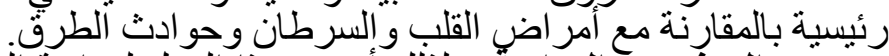

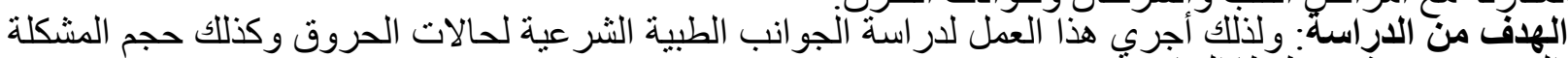

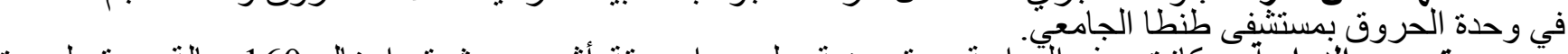

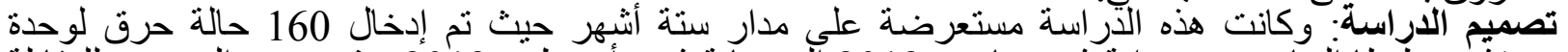

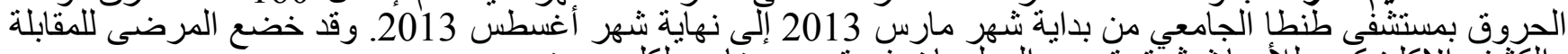

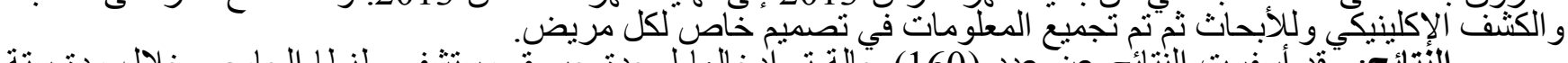

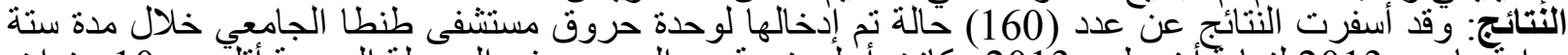

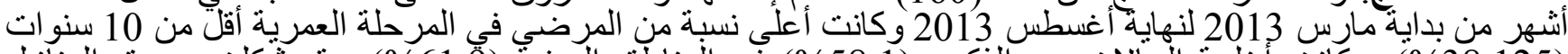

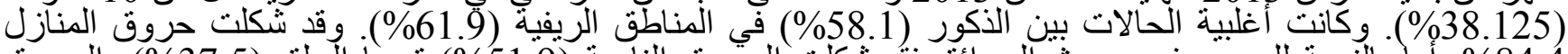

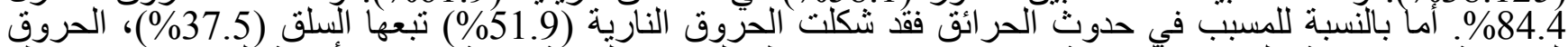

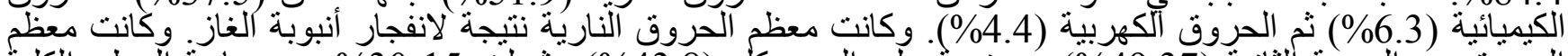

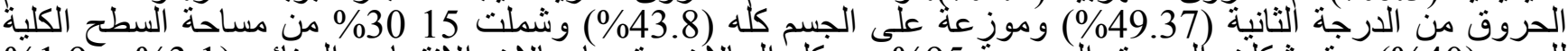

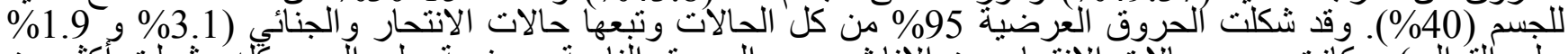

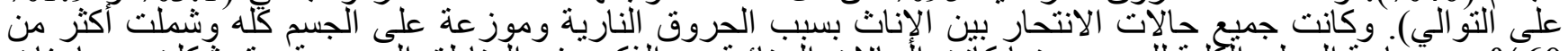

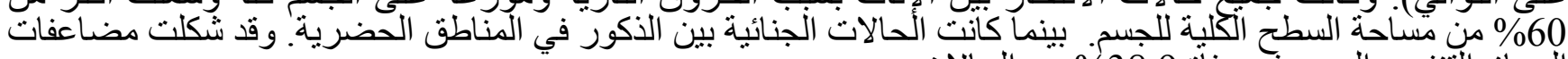

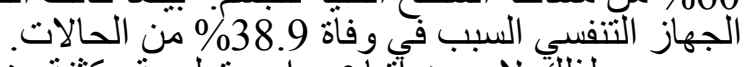

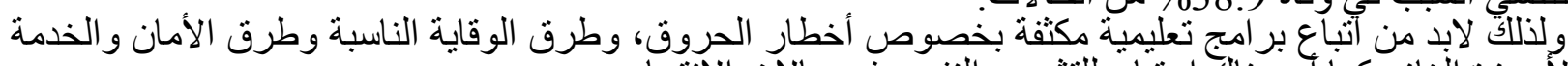

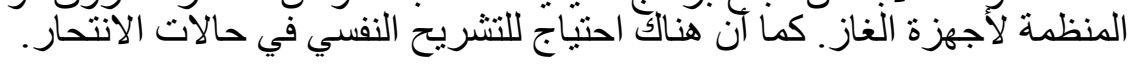

